\title{
Alexithymia and Quality of Life in Adult Patients with Juvenile Idiopathic Arthritis
}

\author{
Marta Dzhus
}

\begin{abstract}
Patients with chronic pain disturb not only quality of life (QL) but also develop difficulties in describing their feelings. Prolonged pain, stress, pathological conditions and related emotions can alter the perceived sensation of pain. The aim of our study was to study the QL and the level of alexithymia in adult patients with different types of juvenile idiopathic arthritis (JIA).

Materials and methods. 173 young people aged 18-40 years old were examined: 118 adult patients with different ILAR variants of JIA, 30 patients with ankylosing spondylitis (AS) and 25 healthy young people. The QL was assessed using the Short-Form-36 questionnaire (SF36) with further assessing the level of alexithymia by Toronto alexithymia scale (TAS-20).

Results. The analysis of QL shows that PCS $(44.8 \pm 9.9)$ was significantly lower $(p=0.001)$ in patients with JIA than in healthy subjects $(55.7 \pm 6.9)$ of the corresponding age and sex, but did not differ from patients with AS (42.3 \pm 7.5$)$. Patients with JIA had lower physical $(p=0.001)$, role functioning $(p=0.001)$ and bodily pain $(p=0.001)$ compared with healthy, with no difference from patients with AS. In the distribution of patients with JIA in groups by the level of alexithymia, differences in QL were not revealed by MCS or PCS and scales related with them. The relationship analysis between the alexithymia and QL in patients with JIA shows, that elevated and high levels of alexithymia were related with low levels of MCS ( $p<0.05)$, role functioning $(p<0.05)$, mental health $(p<0.05)$. PCS and physical functioning did not affect the level of alexithymia in adult patients with JIA. PCS, role functioning, bodily pain, and general health were the lowest in patients with poly-articular JIA. However patients with oligo-, poly-articular, enthesyte-related JIA had no differences on scales related to PCS. Patients with poly-JIA with elevated and high levels of alexithymia revealed significantly lower social $(p<0.05)$ and role $(p<0.05)$ functioning, mental health $(p<0.05)$ compared to patients without alexithymia. The presence of low bodily pain in alexithymic patients was found. Signs of alexithymia were found in $90 \%$ and $85 \%$ of adult patients with the oligo-arthritis and enthesyte-related JIA, respectively. The comparison of the QL in patients with oligo-arthritis and enthesitis-related JIA with different levels of the alexithymia shows no significant differences.

Conclusions. $85.2 \%$ of adult patients with different variants of JIA have elevated and high levels of alexithymia. Adult patients with JIA have lower physical functioning than healthy individuals of the same age and sex, although they do not differ from the control group and AS group on psychological functioning and related vitality, social and role functioning, and mental health. The presence of alexithymia is related with a low level of psychological functioning, role functioning, mental health. However, physical functioning did not affect the level of alexithymia in adult patients with JIA. Patients with poly-JIA have the lowest physical, role function, bodily pain and general health, but according to the psychological functioning there were no differences between different variants of JIA in adulthood. Patients with poly-JIA with elevated and high levels of alexithymia have significantly lower social $(p<0.05)$, role $(p<0.05)$ functioning and mental health $(p<0.05)$ compared to patients without signs of alexithymia.
\end{abstract}

Keywords

juvenile idiopathic arthritis; adult age; quality of life; alexithymia

Bohomolets O.O. National Medical University, Kyiv, Ukraine

Corresponding author: dzhusm@yahoo.co.uk

\section{Problem statement and analysis of the recent research}

Chronic pain not only affects the quality of patients' life (QL) but causes difficulties in describing one's feelings. Prolonged pain, stress, presence of disease and related emotions can alter the perceived sensation of pain [1-3].

Juvenile idiopathic arthritis (JIA) is a group of diseases in children less than 16 years of age. It is accompanied by the development of arthritis, prolonged pain and in some cases leads to functional disorders of joints and ankyloses. In adulthood
30-50\% of patients continue to have active disease, accompanied by articular and extra-articular damages having a negative impact on the QL. The latter is assessed according to the life quality questionnaire SF-36 covering both physical and psychological wellness of patients. This questionnaire helps to evaluate different spheres of life connected with physical functioning, intensity of pain, vitality. Mental functioning of patients is studied as well. Our previous research was focused on the QL assessment in young adults at the transition period from children to adult rheumatologic care [4]. It is known 
that, JIA continues in adulthood and the QL is affected by problems of adult life. Therefore, we performed our research further to assess the QL not only at the transition period to adult rheumatologic care but in adulthood. Furthermore, in a number of cases patients with chronic diseases cannot adequately express their feelings or give a correct description of their condition. In such cases the term "alexithymia" is used in order to describe problems connected with effective cognitive processing and regulation of emotions. Such patients experience difficulty to identify and describe their feelings, distinguish between feelings and bodily sensations, have a constricted imagery, as evidenced by a paucity of fantasies, and a stimulus-bound, externally oriented cognitive style [5] (Taylor et al., 1997). Alexithymia is most frequently assessed by Toronto alexithymia scale (TAS-20), which is the most widely used alexithymia tool in referred scientific research and its psychometric properties were validated in different populations and cultures [6]. Therefore, it is considered that TAS-20 can be used as the only method of assessment [6]. The TAS-20 questionnaire consists of three subchapters used to assess different components of alexithymia: 1) difficulty in identifying feelings, for example, impossibility to identify physical sensations as features of affective feelings or impossibility to differentiate various emotions; 2) difficulty in describing feelings, for example, lack of accurate words to describe feelings; 3 ) externally oriented thinking is more interested in the objective outer world or factual events than in inner world of thoughts, feelings, and subjective interpretations of events [7].

The objective of our research was to study the QL and the level of alexithymia in adult patients with different types of juvenile idiopathic arthritis.

\section{Materials and methods of the research}

173 young people aged 18-40 years were examined: 118 adult patients with different JIA variants irrespective of presence or absence of active inflammation at the moment of examination without severe additional pathology, 30 patients with central and peripheral forms of ankylosing spondylitis (AS) and 25 healthy young people of corresponding age and sex who constituted the group of comparison and control, respectively. The research did not include patients with systemic JIA, organic brain pathology, encephalopathy connected with arterial hypertension, diabetes, chronic kidney insufficiency; GFR $<90 \mathrm{ml} / \mathrm{min}$.

The group included patients from different regions of Ukraine diagnosed with JIA in childhood according to the classification criteria of the International League of Associations for Rheumatology - ILAR, Durban 1997, Edmonton 2001 [8] over the period of 1984-2014. All patients with JIA over 18 years of age were examined by adult rheumatologists in the outpatient or inpatient settings on the basis of Oleksandrivska Municipal Clinical Hospital in Kyiv over the period of April 2015 - December 2017.

The QL of patients with JIA, AS and the control group was assessed using the Short-Form-36 questionnaire. SF-36 is multi-purpose short-form health survey with 36 questions [9], which was assessed using the Swedish version of the Medical Outcomes Study Short Form-36 Health Survey (SF-36), a validated 36-item questionnaire [9] comprising 4 domains of physical health: physical functioning (PF), role physical (RP), bodily pain (BP), and general health $(\mathrm{GH})$; and 4 domains of mental health: vitality (VT), social functioning (SF), role emotional (RE), and mental health (MH). Scores range from 0 to 100 , higher score reflecting better health. The 8 subscales can be summarized to 1 physical component score (PCS) and 1 mental component score (MCS) standardized to a mean (SD) value of 50 .

We used licensed access (License QM037587) for noncommercial academic research from the Office of Graduate Studies and Research (OGSR), granted by OptumInsight Life Sciences, Inc. This version includes new general norms of 2009 for the USA population alongside general population norms of 1998. After the assessment of the QL, irrespective of its results, all patients with JIA were given Toronto alexithymia scale questionnaire (TAS-20) in order to assess a level of alexithymia. Questionnaires were distributed among 118 patients, 108 of whom $(91.5 \%)$ provided their response. The assessment was carried out according to the number of points, i.e. 62 points and less were considered as a normal range, 63-73 points - the "risk group" of alexithymia, and over 74 points - alexithymia.

Patient's general characteristic is shown in Table 1. There were $44.9 \%$ of male patients with the mean age of 23.3 and mean disease duration 12.7 years. The majority of patients had persistent oligo-arthritis, RF-negative polyarthritis and enthesitis-related arthritis. The majority of patients received as disease modifying therapy methotrexate and systemic glucocorticoids (GC) $(58 \%)$ at the moment of examination or prior to it.

Table 1. Clinical characteristic of patients with JIA

\begin{tabular}{l|c}
\hline Parameters & Patients with JIA (n=118) \\
\hline Male, $\mathrm{n}(\%)$ & $53(44.9 \%)$ \\
Age, years (min-max) & $23.3(17.2-41.3)$ \\
Disease duration, years (min- & $12.7(1.3-27.6)$ \\
max) & $9.04(5.2-11.9)$ \\
Age at the disease onset, & \\
years (min-max) & $33(28 \%)$ \\
\hline \multicolumn{2}{c}{ Distribution of patients according to JIA types } \\
\hline RF(-) polyarthritis; $n(\%)$ & $9(7.6 \%)$ \\
Persistent oligoarthritis; & $36(30.5 \%)$ \\
$\mathrm{n}(\%) \quad$ oligoarthritis; & $20(16.9 \%)$ \\
Extended & \\
$\mathrm{n}(\%) \quad 20(16.9 \%)$ \\
Enthesitis-related arthritis; \\
$\mathrm{n}(\%)$
\end{tabular}


Descriptive statistical methods were used for analysis. Data is presented as Mean \pm Standard deviation (SD) for continuous variables in cases of normal distribution of data, and median (25\% quartile; $75 \%$ quartile) in the opposite case. Alongside, indices of minimum and maximum are provided. The distributional adequacy of data was tested by means of Kolmogorov-Smirnov nonparametric test. Student's and Mann-Whitney's tests and dispersion analysis were applied to compare groups under research on the quantitative basis, while Pearson's test $\chi 2$ was used to determine quality. The probability index $\mathrm{p}<0.05$ was considered as statistically significant. The analysis relied on the programs "Statistica 6.0" Copyright StatSoft, Inc.

\section{Results of the research and their discussion}

The analysis of the QL of patients with different JIA variants according to SF 36 shows (Table 2) that physical component score (PCS 44.8 \pm 9.9$)$ was significantly lower $(p=0.001)$ in patients with JIA than in healthy individuals $(55.7 \pm 6.9)$ of corresponding age and sex, but did not differ from patients with AS (PCS 42.3 \pm 7.5$)$. Thus, patients with JIA had lower physical $(\mathrm{p}=0.001)$ and $\mathrm{RF}(\mathrm{p}=0.001)$, and $\mathrm{BP}(\mathrm{p}=0.001)$ compared with healthy individuals, with no difference from patients with AS. However, patients with JIA did not differ from the control group and comparison group by the level of mental component score (MCS), vitality, social functioning, RE and mental health.

We suspected that patients, who have been ill since early age adapted to their condition, learned how to live with chronic pain and therefore cannot verbalize their complaints and adequately evaluate their condition. Therefore, patients with JIA were surveyed on alexithymia according to Toronto scale (TAS-20). However, having classified all patients with JIA into 3 groups according to alexithymia marker (group I - up to 62 points, alexithymia markers are absent; group II - 63-73 points, the group under the risk of developing alexithymia; and group III - over 74 points - alexithymia) we did not detect any differences in the quality of life (Table 3) either in terms of psychological or physical wellness and related scales. This proves that in JIA patients physical wellness is affected more than psychological.

We compared the QL in patients without alexithymia, with patients with elevated and high levels of alexithymia (Table 4). The elevated and high levels of alexithymia were connected with the low level of psychological wellness $(\mathrm{p}<0.05)$, emotional functioning $(\mathrm{p}<0.05)$, mental health $(\mathrm{p}<0.05)$. However, physical wellness (PCS) and physical functioning did not affect the level of alexithymia in adult patients with JIA.

All patients were divided into 3 groups depending on ILAR variant of JIA (Table 5): group I - 42 patients with RF-positive and RF-negative poly-articular JIA variant; group II - 56 patients with persistent and extended oligo-articular JIA variant; and group III - 20 patients with enthesytis-related JIA variant.
As seen from the data, physical wellness is the lowest in patients with poly-articular JIA variant. The same changes can also be observed in the scales of role functioning, intensity of pain, and general health. However, these patients did not differ by psychological wellness markers.

On evaluating TAS-20 in adult patients with JIA it was concluded that only 16 of them $(14.8 \%)$ did not have alexithymia, while 92 persons $(85.2 \%)$ had elevated and high levels of alexithymia. Since patients with poly-articular JIA variants had lower level of physical wellness than patients with other JIA variants we decided to compare the QL markers in these patients using alexithymia scale (table 6). It was concluded that $18.9 \%$ of patients with poly-articular JIA variants did not have alexithymia while $80 \%$ of them had elevated or high levels of alexithymia. As seen from table 6, patients with poly-articular JIA variants ( $\mathrm{RF}+$ and $\mathrm{RF}-$ ) with elevated and high levels of alexithymia have lower indices of social $(\mathrm{p}<0.05)$ and role $(\mathrm{p}<0.05)$ functioning, and mental health $(\mathrm{p}<0.05)$ compared to patients without alexithymia. However, the presence of low bodily pain in alexithymic patients is unclear. It is most probably connected with a larger dispersion (Min 10; Max 100) of the index in the alexithymia group compared to the group of patients without alexithymia (Min 41; Max 86) and a small number of patients in this group.

Signs of alexithymia were found in $90 \%$ and $85 \%$ of adult patients with the oligo-arthritis and enthesite-related variants of the JIA, respectively. The comparison of the QL in patients with oligo-arthritis- and enthesite-related JIA variants with different levels of alexithymia shows no significant differences (tables 7 and 8).

\section{Discussion}

Foster H. et al studied the outcome in 82 adults with juvenile idiopathic arthritis a quality of life study [10]. Our research is to some extent different from their results due to a higher number of examined patients (135 compared to 82): we did not find any differences in terms of general health, role emotions, and social functioning unlike the research [10], although, indices of lower mental health, role functioning and the bodily pain in adult patients with JIA coincide. M. Di Tella òa L. Castelli focused their research on the level of alexithymia in patients with diseases accompanied by chronic pain. The authors showed that patients with alexithymia have more pronounced pain syndrome [11], however, in our research the intensity of pain by SF36 in patients with alexithymia was lower than in patients without alexithymia. Since alexithymia is a complex process observed in different pathological conditions, in particular psychosomatic disorders [12], it can be considered a deficit of cognitive thinking and emotional regulation [13]. It is characterized by the difficulty to express feelings and separate emotional and physical feelings, difficulties related to subjective feelings, paucity of fantasies [13]. The role of psychological factors for the understanding of persistent pain syndrome has been sufficiently proved [14, $15,16,17]$, however, the character of these disorders or high 
Table 2. Comparison of the QL in patients with JIA, AS and healthy individuals according to SF36

\begin{tabular}{l|c|c|c|c|c|c}
\hline & Healthy $(\mathrm{n}=25)$ & Patients with JIA $(\mathrm{n}=135)$ & Patients with AS $(\mathrm{n}=30)$ & $\mathrm{p} 1$ & $\mathrm{p} 2$ & $\mathrm{p} 3$ \\
\hline PCS & $55.7 \pm 6.9(39.3 ; 66.2)$ & $44.8 \pm 9.9(17.2 ; 64.8)$ & $42.3 \pm 7.5(33.1 ; 55.3)$ & $0.001^{*}$ & $0.001^{*}$ & 0.172 \\
MCS & $45.1 \pm 11.7(17.4 ; 60.4)$ & $45.7 \pm 11.1(18.4 ; 66.4)$ & $44 \pm 10(27.3 ; 58.9)$ & 0.889 & 0.594 & 0.515 \\
PF & $94.7 \pm 8.7(70 ; 100)$ & $70.9 \pm 25.4(0 ; 100)$ & $68.5 \pm 19.4(25 ; 95)$ & $0.001^{*}$ & $0.001^{*}$ & 0.301 \\
RF & $83.8 \pm 19.5(37.5 ; 100)$ & $60.8 \pm 33(0 ; 100)$ & $47.4 \pm 28.9(0 ; 100)$ & $0.007^{*}$ & $0.001^{*}$ & $0.039^{*}$ \\
BP & $84.5 \pm 21.6(20 ; 100)$ & $55.3 \pm 26.6(0 ; 100)$ & $48.1 \pm 15.2(22 ; 84)$ & $0.001^{*}$ & $0.001^{*}$ & 0.197 \\
GH & $60.1 \pm 17.1(15 ; 82)$ & $51.5 \pm 22.9(5 ; 100)$ & $49.3 \pm 15.2(25 ; 92)$ & 0.083 & $0.006^{*}$ & 0.732 \\
VT & $59.8 \pm 20(12.5 ; 93.8)$ & $54.6 \pm 21.1(6.3 ; 100)$ & $49.7 \pm 17.8(12.5 ; 87.5)$ & 0.328 & $0.048^{*}$ & 0.228 \\
SF & $80.5 \pm 18.2(50 ; 100)$ & $71.8 \pm 24.1(0 ; 100)$ & $66.7 \pm 24.9(12.5 ; 100)$ & 0.201 & 0.090 & 0.315 \\
RE & $75 \pm 26.7(25 ; 100)$ & $67.2 \pm 33.4(0 ; 100)$ & $59.4 \pm 33.2(0 ; 100)$ & 0.440 & 0.141 & 0.234 \\
MH & $68.4 \pm 18.9(25 ; 100)$ & $66 \pm 20.1(10 ; 100)$ & $64.2 \pm 17.2(30 ; 100)$ & 0.842 & 0.389 & 0.470 \\
\hline
\end{tabular}

PCS - physical component score;

MCS - mental component score;

PF-physical functioning;

RF- role functioning;

$\mathrm{BP}$ - intensity of pain;

GH - general health;

VT - vitality;

$\mathrm{SF}$ - social functioning;

$\mathrm{RE}$ - role emotions;

$\mathrm{MH}$ - mental health;

p1 - comparison of groups of healthy people and patients with JIA;

p2 - comparison of groups of healthy people and patients with AS;

p3 - comparison of groups of patients with JIA and AS.

Table 3. Connection between alexithymia and the quality of life in patients with JIA

\begin{tabular}{l|c|c|c|c}
\hline & Normal & Elevated & High & $\mathrm{p}$ \\
\hline PCS & $44.9 \pm 9.6(24.2 ; 59.9)$ & $44.6 \pm 12.3(17.2 ; 61.9)$ & $44.4 \pm 9(22.3 ; 64.8)$ & 0.976 \\
MCS & $51.4 \pm 10.2(29.1 ; 65.4)$ & $46.7 \pm 9.4(21.3 ; 60.9)$ & $45.2 \pm 11.1(18.4 ; 66.4)$ & 0.089 \\
PF & $73.1 \pm 23.7(15 ; 100)$ & $69.6 \pm 31.2(0 ; 100)$ & $70.2 \pm 24.1(10 ; 100)$ & 0.901 \\
RF & $62.9 \pm 38.6(0 ; 100)$ & $64.3 \pm 38.4(0 ; 100)$ & $59.2 \pm 31.1(0 ; 100)$ & 0.773 \\
BP & $58.4 \pm 21.1(22 ; 100)$ & $56.1 \pm 31.9(0 ; 100)$ & $54.5 \pm 25.2(0 ; 100)$ & 0.848 \\
GH & $60.9 \pm 21.3(30 ; 100)$ & $51 \pm 25.2(20 ; 100)$ & $50.3 \pm 21.7(5 ; 87)$ & 0.217 \\
VT & $59 \pm 23.4(18.8 ; 100)$ & $53.9 \pm 21.2(6.3 ; 100)$ & $55.4 \pm 19.8(12.5 ; 93.8)$ & 0.740 \\
SF & $73.4 \pm 24.9(12.5 ; 100)$ & $71.9 \pm 26.9(12.5 ; 100)$ & $71.7 \pm 22.8(0 ; 100)$ & 0.965 \\
RE & $81.8 \pm 31.1(0 ; 100)$ & $74.7 \pm 29.2(0 ; 100)$ & $63.6 \pm 34.7(0 ; 100)$ & 0.079 \\
MH & $77.5 \pm 17.3(40 ; 100)$ & $64.6 \pm 20.5(10 ; 90)$ & $66.2 \pm 19(20 ; 100)$ & 0.074 \\
\hline
\end{tabular}

levels of psychopathology in patients with chronic pain have not been fully clarified [18].

A number of research shows that alexithymia is connected with pain and pain related disfunctions [19, 20]. Despite contradictory results $[21,22]$ there was found a strong connection between alexithymia and the intensity of pain. The available research shows strong presence of alexithymia, especially difficulty to express feelings, under chronic pain syndrome. However, the connection between alexithymia and the intensity of pain is not always clear, and in some research this connection was not found [23], which coincides with the results of our research. It may be indirectly connected with other negative factors, in particular depression $[24,25,26$, 27]. Previous research also confirmed these results without correlation [22, 28], positive correlation or mixed results [29].

An explanation can be attributed to the multidimensional nature of pain including affective and sensory [30] components. The sensory component is connected with the intensity of pain while the affective one - with an unpleasant experience of pain. Research accounting for this difference found a specific connection only between alexithymia and affective dimension of pain in patients with chronic pain $[19,20]$. The affective component of pain depends upon the limbic system of brain responsible for the regulation and processing of emo- 
Table 4. Connection between alexithymia and the quality of life in patients with JIA

\begin{tabular}{l|c|c|c}
\hline & Normal & Elevated and High & $\mathrm{p}$ \\
\hline PCS & $44.9 \pm 9.6(24.2 ; 59.9)$ & $44.4 \pm 9.8(17.2 ; 64.8)$ & 0.743 \\
MCS & $51.4 \pm 10.2(29.1 ; 65.4)$ & $45.5 \pm 10.7(18.4 ; 66.4)$ & 0.035 \\
PF & $73.1 \pm 23.7(15 ; 100)$ & $70.1 \pm 25.7(0 ; 100)$ & 0.657 \\
RF & $62.9 \pm 38.6(0 ; 100)$ & $60.3 \pm 32.7(0 ; 100)$ & 0.777 \\
BP & $58.4 \pm 21.1(22 ; 100)$ & $54.9 \pm 26.7(0 ; 100)$ & 0.610 \\
GH & $60.9 \pm 21.3(30 ; 100)$ & $50.4 \pm 22.4(5 ; 100)$ & 0.061 \\
VT & $59 \pm 23.4(18.8 ; 100)$ & $55.1 \pm 20(6.3 ; 100)$ & 0.480 \\
SF & $73.4 \pm 24.9(12.5 ; 100)$ & $71.7 \pm 23.6(0 ; 100)$ & 0.789 \\
RE & $81.8 \pm 31.1(0 ; 100)$ & $66 \pm 33.7(0 ; 100)$ & 0.046 \\
MH & $77.5 \pm 17.3(40 ; 100)$ & $65.8 \pm 19.3(10 ; 100)$ & 0.022 \\
\hline
\end{tabular}

Table 5. Comparison of the quality of life in patients with different JIA variants

\begin{tabular}{l|c|c|c|c}
\hline & Poly-articular variant $(\mathrm{n}=42)$ & $\begin{array}{c}\text { Oligo-articular variant } \\
(\mathrm{n}=56)\end{array}$ & $\begin{array}{c}\text { Enthesitis-related variant } \\
(\mathrm{n}=20)\end{array}$ & $\mathrm{p}$ \\
\hline PCS & $41.8 \pm 9.2(22.3 ; 61.7)$ & $47.9 \pm 8.5(28.2 ; 64.8)$ & $45.8 \pm 11.7(22.1 ; 61.9)$ & $0.007^{*}$ \\
MCS & $46.6 \pm 10.9(25.7 ; 65.4)$ & $45.1 \pm 11.2(18.4 ; 66.4)$ & $46.4 \pm 12.6(20.8 ; 63)$ & 0.769 \\
PF & $68.3 \pm 25.4(10 ; 100)$ & $78.7 \pm 17.4(35 ; 100)$ & $71.3 \pm 27.8(0 ; 100)$ & $0.042^{*}$ \\
RF & $56.8 \pm 33.9(0 ; 100)$ & $65.7 \pm 30.3(0 ; 100)$ & $63.4 \pm 36.1(0 ; 100)$ & 0.406 \\
BP & $48.7 \pm 24.1(0 ; 100)$ & $60.8 \pm 23.7(22 ; 100)$ & $60.3 \pm 31.6(0 ; 100)$ & $0.042^{*}$ \\
GH & $43.7 \pm 20.9(15 ; 100)$ & $57.8 \pm 21.5(10 ; 100)$ & $54.4 \pm 27.2(5 ; 100)$ & $0.009^{*}$ \\
VT & $51.9 \pm 21.2(6.3 ; 100)$ & $58.4 \pm 19(18.8 ; 93.8)$ & $55 \pm 25.6(12.5 ; 100)$ & 0.313 \\
SF & $71.1 \pm 24(12.5 ; 100)$ & $73.4 \pm 23.2(12.5 ; 100)$ & $72.5 \pm 23.9(37.5 ; 100)$ & 0.892 \\
\hline
\end{tabular}

Table 6. Comparison of the quality of life in patients with poly-articular JIA variant using alexithymia scale

\begin{tabular}{l|c|c|c}
\hline & Absence of alexithymia $(\mathrm{n}=7)$ & $\begin{array}{c}\text { Elevated and high levels of alexithymia } \\
(\mathrm{n}=30)\end{array}$ & $\mathrm{p}$ \\
\hline PCS & $43.4 \pm 9.9(24.2 ; 51.5)$ & $40.9 \pm 8.7(22.3 ; 56.1)$ & 0.498 \\
MCS & $51.6 \pm 12.2(29.1 ; 65.4)$ & $45.8 \pm 9.8(25.7 ; 61.2)$ & 0.189 \\
PF & $75.7 \pm 27.3(15 ; 95)$ & $65.2 \pm 25.4(10 ; 95)$ & 0.335 \\
RF & $58 \pm 12.5(0 ; 100)$ & $56.5 \pm 12.7(0 ; 100)$ & 0.914 \\
BP & $62.6 \pm 16.6(41 ; 84)$ & $45 \pm 22.5(10 ; 100)$ & $0.038^{*}$ \\
GH & $49.6 \pm 18.1(30 ; 87)$ & $41.4 \pm 20.3(15 ; 82)$ & 0.319 \\
VT & $51.8 \pm 21.3(18.8 ; 75)$ & $51.4 \pm 20(6.3 ; 82)$ & 0.966 \\
SF & $82.1 \pm 12.2(75 ; 100)$ & $68.8 \pm 24.5(12.5 ; 100)$ & $0.041^{*}$ \\
RE & $85.7 \pm 26.2(33.3 ; 100)$ & $68.6 \pm 28.4(0 ; 100)$ & $0.049^{*}$ \\
MH & $74.3 \pm 21.7(40 ; 100)$ & $62.4 \pm 20.4(10 ; 95)$ & 0.178 \\
\hline
\end{tabular}

tions. Due to this reason it is highly possible that research applying one-dimensional assessment of pain in patients with chronic pain could not find a connection with alexithymia. Another possible explanation, particularly of the mediating role of psychological problem, can be attributed to the fact that people with high degree of alexithymia not only have limited abilities to show their emotions but also considerable difficulties in verbal communication and cannot secure other people's aid [13]. This can lead to the intensifying of emotional stress and consequently can have a negative influence on the level of depression and anxiety. Therefore, further research on the nature of such association is necessary applying more precise methods to assess both pain and alexithymia. In particular, it would be useful to apply multidimensional methods to assess pain in order to differentiate both pain components.

Thus, prospective research is needed to specify the nature of connection between alexithymia and chronic pain in JIA, the role of alexithymia for the development and evolution of pain, and the influence of alexithymia on psychopathological symptoms in patients with chronic pain. Understanding how 
Table 7. Comparison of the quality of life markers in patients with poly-articular JIA variants using alexithymia scale

\begin{tabular}{l|c|c|c}
\hline \multirow{2}{*}{} & \multicolumn{2}{|c}{ Alexithymia } & \multirow{2}{*}{$\mathrm{p}$} \\
\cline { 2 - 3 } & Normal $(\mathrm{n}=5)$ & Elevated and high $(\mathrm{n}=45)$ & 0.333 \\
PCS & $43.6 \pm 10.4(30 ; 54.3)$ & $47.5 \pm 8.3(28.2 ; 64.8)$ & 0.663 \\
MCS & $48.2 \pm 11.7(33.5 ; 63.1)$ & $46 \pm 10.6(18.4 ; 66.4)$ & 0.192 \\
PF & $68 \pm 26.4(35 ; 95)$ & $79 \pm 16.6(40 ; 100)$ & 0.455 \\
RF & $55 \pm 14.7(0 ; 100)$ & $66 \pm 29.3(0 ; 100)$ & 0.187 \\
BP & $46 \pm 21.4(22 ; 72)$ & $60.9 \pm 23.8(22 ; 100)$ & 0.306 \\
GH & $67.2 \pm 11.6(55 ; 82)$ & $57.1 \pm 21.3(10 ; 100)$ & 0.782 \\
VT & $62.5 \pm 28(25 ; 93.8)$ & $60.1 \pm 17.2(25 ; 93.8)$ & 0.116 \\
SF & $57.5 \pm 18.1(12.5 ; 100)$ & $74.7 \pm 20.9(25 ; 100)$ & 0.690 \\
RE & $61.7 \pm 41.5(0 ; 100)$ & $68.1 \pm 33.5(0 ; 100)$ & 0.205 \\
MH & $79 \pm 15.2(60 ; 100)$ & $68.5 \pm 18.5(20 ; 100)$ & \\
\hline
\end{tabular}

Table 8. Comparison of the quality of life markers in patients with poly-articular JIA variants using alexithymia scale

\begin{tabular}{l|c|c|c}
\hline \multirow{2}{*}{} & Normal $(\mathrm{n}=3)$ & Alexithymia & $\mathrm{p}$ \\
\cline { 2 - 3 } & $45.5 \pm 12.5$ & Elevated and high $(\mathrm{n}=17)$ & 0.990 \\
PCS & $57.6 \pm 5.4$ & $45.9 \pm 12(22.1 ; 61.9)$ & 0.093 \\
MCS & $75 \pm 21.8$ & $44.4 \pm 12.5(20.8 ; 63)$ & 0.756 \\
PF & $75 \pm 25$ & $70.6 \pm 29.3(0 ; 100)$ & 0.689 \\
RF & $64.3 \pm 31.4$ & $61.4 \pm 38(0 ; 100)$ & 0.742 \\
BP & $66.7 \pm 32.5$ & $59.5 \pm 32.5(0 ; 100)$ & 0.476 \\
GH & $68.8 \pm 28.6$ & $52.2 \pm 26.6(5 ; 100)$ & 0.416 \\
VT & $79.2 \pm 19.1$ & $52.6 \pm 25.2(12.5 ; 100)$ & 0.689 \\
SF & $100 \pm 0$ & $71.3 \pm 24.9(37.5 ; 100)$ & 0.093 \\
RE & $85 \pm 15$ & $58.8 \pm 39.4(0 ; 100)$ & 0.216 \\
MH & & $67.9 \pm 20.8(25 ; 100)$ & \\
\hline
\end{tabular}

much alexithymia contributes to chronic pain will allow to understand the aetiology of pain and will help to apply a more precise treatment of it based on a patient's needs, with the effect both on physical and psychological aspects.

\section{Conclusions}

1. $85.2 \%$ of adult patients with different variants of JIA have elevated and high levels of alexithymia.

2. Adult patients with JIA have lower physical functioning than healthy individuals of the same age and sex, although they do not differ from the control group and AS group according to the level of psychological wellbeing and related vitality, social and role functioning, and mental health. The presence of alexithymia is related with a low level of psychological functioning, role functioning, mental health.

3. The presence of alexithymia is connected with a low level of psychological wellbeing, role functioning, mental health. However, physical functioning did not affect the level of alexithymia in adult patients with JIA.

4. Patients with poly-JIA have the lowest physical, role function, bodily pain and general health, but according to the psychological functioning there were no differences between different variants of JIA in adulthood.

5. Patients with poly-JIA (RF+ and RF-) with elevated and high levels of alexithymia have significantly lower social $(p<0.05)$, role $(p<0.05)$ functioning and mental health $(\mathrm{p}<0.05)$ compared to patients without signs of alexithymia.

\section{References}

[1] Apkarian V, Baliki M, Geha P. Towards theory of chronic pain. Prog Neurobiol. 2009; 87: 8197. DOI: https://doi.org/10.1016/j. pneurobio.2008.09.018

[PMid: 18952143 PMCid:PMC2650821]

[2] Apkarian V, Hashmi J, Baliki M. Pain and the brain: specificity and plasticity of the brain in clinical chronic pain. Pain. 2011; 152: 49-64. DOI: https://doi.org/ $10.1016 / j . p a i n .2010 .11 .010$ [PMid:21146929 PMCid:PMC3045648]

[3] Lumley MA, Cohen J, Borszcz G et al. Pain and emotion: A biopsychosocial review of recent research. J 
Clin Psychol. 2011; 67: 942-968. DOI: https : / / doi . org/10.1002/jclp. 20816 [PMid:21647882 PMCid:PMC3152687]

[4] Dzhus MB. Influence of juvenile idiopathic arthritis on the quality of life of young people during the transition period to the adult rheumatologic service. Psykhosomatychna medytsyna ta zahalna praktyka. 2017; 2(4), å020478-å020478 DOI: https://doi.org/ $10.26766 / \mathrm{pmgp}$.v2i4.78

[5] Taylor GJ, Bagby RM, Parker JDA. The twentyitem Toronto alexithymia scale: IV. Reliability and factorial validity in different languages and cultures. Journal of Psychosomatic Research. 2003; 55: 277-283. DOI: https://doi.org/10.1016/ s0022-3999(02)00601-3

[6] Taylor G.J., Bagby R.M., Luminet O. Assesment of alexithymia: Self-report and observer-rated measure in BarOn R, JDA (eds): the Hand-book of Emotional Intelligence. San-Francisco, Jossey-Bass, 2000; 301-319.

[7] Kelly Paull, Alexithymia, attachment and psychological wellbeing in young adults leaving care. Dissertation submitted in partial fulfilment of the DClinPsy at Cardiff University and the South Wales Doctoral Programme in Clinical Psychology, 2013; 127.

[8] Petty RE, Southwood TR, Manners P et al. International League of Associations for Rheumatology classification of juvenile idiopathic arthritis: second revision, Edmonton 2001. J. Rheumatol. 2004; 31: 390-392. [PMid:14760812]

[9] Sullivan M, Karlsson J, Ware JR. The Swedish SF36 Health Survey. Evaluation of data quality, scaling assumptions, reliability and construct validity across general populations in Sweden. Soc Sci Med. 1995; 41: 1349-1358. DOI: https : // doi .org/10. $1016 / 0277-9536$ (95) $00125-\mathrm{Q}$

[10] Foster HE, Marshall N, Myers A et al. Outcome in Adults With Juvenile Idiopathic Arthritis A Quality of Life Study. Arthritis \& Rheumatism. 2003; 48 (3): 767-775. DOI: https: / / doi .org/10.1002/art. 10863 [PMid:12632431]

[11] Di Tella M, Castelli L. Alexithymia in Chronic Pain Disorders Curr Rheumatol Rep. 2016; 18:41. DOI: https : //doi.org/10.1007/s11926-016-0592-x

[12] Taylor GJ. Recent development in alexithymia theory and research. Can J Psychiatry. 2000; 45:134-142. DOI: https://doi.org/10.1177/ 070674370004500203 [PMid:10742872]

[13] Taylor GJ, Bagby RM, Parker JDA. Disorders in affect regulation: alexithymia in medical and psychiatric illness. Cambridge (UK): Cambridge University
Press; 1997. DOI: https://doi.org/10.1017/ CB09780511526831

[14] Dersh J, Gatchel RJ, Polatin P. Chronic spinal disorders and psy- chopathology: Research findings and theoretical considerations. Spine. 2001; 1: 88-94. DOI: https : / / doi.org/10.1016/S1529-9430(01)00017-1

[15] Sullivan MD. Finding pain between minds and bodies. Clin J Pain. 2001; 17: 146-56. DOI: https://doi . org/10.1097/00002508-200106000-00007 [PMid:11444716]

[16] Gatchel RJ. Perspectives on pain: A historical review. In: Gatchel RJ, Turk DC, editors. Psychosocial Factors in Pain. New York: The Guilford Press. 1999; 3-17.

[17] Manchikanti L, Fellows B, Singh V. Understanding psychological aspects of chronic pain in interventional pain management. Pain Physician. 2002; 5: 57-82. [PMid:16896359]

[18] Sharp J, Keefe B. Psychiatry in chronic pain: a review and update. Curr Psychiatry Rep. 2005; 7: 213-219. DOI: https://doi.org/10.1007/ s11920-005-0056-x [PMid:15935136]

[19] Huber A, Suman AL, Biasi G et al. Alexithymia in fibromyalgia syndrome: associations with ongoing pain, experimental pain sensitivity and illness behavior. J Psychosom Res. 2009; 66: 425-433. DOI: https : / / doi . org/10.1016/j.jpsychores.2008.11.009 [PMid:19379959]

[20] Lumley MA, Smith JA, Longo DJ. The relationship of alexithymia to pain severity and impairment among patients with chronic myofascial pain: comparisons with self-efficacy, catastrophizing, and depression. J Psychosom Res. 2002; 53: 823-830. DOI: https://doi. org/10.1016/s0022-3999(02)00337-9

[21] Celikel FC, Saatcioglu O. Alexithymia and anxiety in female chron- ic pain patients. Ann Gen Psychiatry. 2006; 5:13. DOI: https://doi.org/ $10.1186 / 1744-859 \mathrm{X}-5-13$ [PMid:16911802 PMCid:PMC1562423]

[22] Cox BJ, Kuch K, Parker JD, et al. Alexithymia in somatoform disorder patients with chronic pain. J Psychosom Res. 1994; 38: 523-527. DOI: https://doi.org/ $10.1016 / 0022-3999$ (94) 90049-3

[23] Castelli L, De Santis F, De Giorgi I et al. Alexithymia, anger and psychological distress in patients with myofascial pain: a case-control study. Front Psychol. 2013; 4: 490. DOI: https://doi.org/10.3389/fpsyg. 2013. 00490 [PMid:23914181 PMCid:PMC3728491] 
[24] Makino S, Jensen MP, Arimura T et al. Alexithymia and chronic pain: The role of negative affectivity. Clin J Pain. 2013; 29: 354-361. DOI: https://doi.org/10. 1097/AJP.0b013e3182579c63 [PMid:23183262]

[25] Saariaho AS, Saariaho TH, Mattila AK et al. Alexithymia and depression in a chronic pain patient sample. Gen Hosp Psychiatry. 2013; 35: 239-245. DOI: https://doi.org/10.1016/j. genhosppsych.2012.11.011 [PMid:23333032]

[26] Shibata M, Ninomiya T, Jensen MP et al. Alexithymia is related with greater risk of chronic pain and negative affect and with lower life satisfaction in a general population: the Hisayama Study. PLoS

[27] Saariaho AS, Saariaho TH, Mattila AK et al. Alexithymia and Early Maladaptive Schemas in chronic pain patients. Scand J Psychol. 2015; 56: 428437. DOI: https://doi.org/10.1111/sjop. 12226 [PMid:26040835]

[28] Friedberg F, Quick J. Alexithymia in Chronic Fatigue Syndrome: association with momentary, recall, and retrospective measures of somatic complaints and emotions. Psychosom Med. 2007; 69: 54-60. DOI: https://doi.org/10.1097/PSY. 0b013e31802b873e [PMid:17244849]

[29] Sayar K, Gulec H, Topbas M. Alexithymia and anger in patients with fibromyalgia. Clin Rheumatol. 2004; 23: 441-448. DOI: https://doi.org/10.1007/ s10067-004-0918-3 [PMid:15278756]

[30] Melzack R, Katz J. The McGill Pain Questionnaire: appraisal and current status. In: Turk DC, Melzack R, editors. Handbook of pain assessment. New York: Guilford Press; 1992; 152-168.

Received: 23 Apr 2017

Revised: 24 May 2017

Accepted: 25 May 2017 